\title{
La literatura posmoderna española: entre el fin de la dictadura y el auge de los mass media
}

Palabras clave: cultura española, medios de comunicación de masas, posmodernismo, literatura española, poesía contemporánea.

\section{Introducción}

Se utiliza el término «literatura posmodernista» (o posmoderna) para referirse a aquella producida a partir de la Segunda Guerra Mundial caracterizada por ciertas peculiaridades que se contraponen a las tendencias del movimiento modernista. Lo cierto es que no existe una definición académica aceptada debido a que no hay distancia temporal para poder analizarla objetivamente. Por lo tanto, la búsqueda de una descripción concreta es complicada ya que tratamos con un término ambiguo y lleno de interpretaciones y contradicciones según el teórico que la estudie. En nuestro trabajo hemos utilizado el planteamiento histórico de Gianni Vattimo expuesto en sus obras Ética de la interpretación (1989) y Nibilismo y emancipación: ética, política, derecho (2004) para tratar el origen de la corriente posmodernista, las propuestas de la monografía de Sobejano-Morán Metaficción española en la posmodernidad (2003) para localizar las primeras expresiones del movimiento en España, así como textos de otros autores como Ensayos sobre el posmodernismo (1993) de Fredric Jameson o la tesis doctoral Ética y posmodernidad (2001) de la investigadora María Sylvia Jaime Garza.

Para el filósofo italiano Gianni Vattimo (2004) se producen dos acontecimientos importantes que marcan el fin de la modernidad y el «ocaso de Occidente», dando pie al movimiento posmoderno. Vattimo explica a qué se refiere con la expresión «el ocaso de Occidente» en su libro Nibilismo y emancipación: 
ética, política, derecho: «esto es de la disolución de la idea de progreso y de historicidad unidireccional, es un hecho de carácter social y político antes que filosófico» (2004: 39). El primer acontecimiento que argumenta es el de la desaparición de los modelos imperialistas y coloniales en la primera mitad del siglo XX, que trajo consigo el desmembramiento de la hegemonía europea y la destrucción de la idea etnocéntrica. Si la modernidad ha terminado, con ella se acaba una línea histórica unitaria en la que el hombre occidental y la sociedad europea suponían el ideal en detrimento del resto de culturas, que para la perspectiva eurocentrista eran inferiores, atrasadas o incluso primitivas. El segundo hito concierne a la aparición y consolidación de los mass media en la sociedad occidental. Con el surgimiento y expansión de los medios de comunicación de masas la propuesta histórica de sentido unitario de la modernidad se diluye en una vorágine de realidades propias que presentan cada medio provocando un caos de «verdades». Si la modernidad impulsaba una sola voz callando a las demás, la posmodernidad trae consigo una realidad formada por tantas voces como medios de comunicación haya. Para el pensamiento posmoderno la verdad absoluta no existe, sino que es el propio lenguaje, como medio estructurado de representación, aquello que construye la realidad. Tras el «giro lingüístico» se impone la idea de que solo el lenguaje es capaz de lograr la verdad objetiva, ya que los hechos son como los signos, es decir, artificiales y subjetivos. Pensar ya no es teorizar sobre la realidad, es construirla. La investigadora Jaime Garza comenta lo siguiente sobre esta nueva forma de comprender el mundo:

Si la modernidad aparece como un manifiesto a la autosuficiencia del hombre, la posmodernidad es la confesión de modestia y desesperanza en la razón. Por eso pregona que no existe «verdad» sólo «verdades». No existe el gran relato de la ciencia, de Dios, de la historia y del progreso, considerados como metarrelatos; sólo existen relatos. La deslegitimación de los metarrelatos es otro de los aspectos que acompañan a las posiciones posmodernas. (Jaime Garza, 2001: 126)

En consecuencia, el posmodernismo nace como negación al modernismo. Por un lado los autores que pudieran ser clasificados como posmodernistas rehúyen del pensamiento ilustrado que esgrimían los modernistas, estos defendían la idea de que la razón podía dar explicación a cualquier fenómeno ocurrido. Por el otro lado, tampoco se acepta su optimismo a través del cual toda la realidad humana podía ser descrita y explicada por el lenguaje. 
El teórico literario Fredric Jameson (1991: 19-20) describe lo que él llama «revuelta posmodernista» como un movimiento donde predominan las representaciones sexuales explícitas, de carácter oscuro, cargado de provocaciones sociales y políticas... el cual busca un grado de subversión que ni el modernismo más radical logró. Afirma que la sociedad contemporánea, lejos de caer en el hostigamiento de la propuesta posmodernista, ha normalizado su mensaje, e incluso institucionalizado parte de él de tal manera que esta actitud subversiva ha pasado a formar parte de la cultura oficial del mundo occidental.

Vattimo llama, en su obra Ética de la interpretación (1989), a la posmodernidad el «fin de la historia», ya que entiende que la historia había sido construida parcialmente por los grupos que ejercían el poder hegemónico en la modernidad. Afirma que la corriente modernista fue desapareciendo en un proceso paulatino, por lo que la posmodernidad es dependiente de ella en tanto en cuanto es la total negación de la modernidad (Blanco Gálvez, 2007: 28). Jean-Francois Lyotard en su libro La condición posmoderna: informe sobre el saber (1979) describe lo posmoderno como una emancipación de la razón y de los metarrelatos, que siendo conceptos totalitarios resultan nocivos para el hombre porque buscan la alienación y homogenización de la sociedad. La posmodernidad se conforma como reivindicación de lo individual y de lo local ante lo universal. Para Lyotard es la «era de la cultura», donde los medios de comunicación se han constituido como medios de poder.

En el sistema actual, basado en un capitalismo feroz, conceptos como el de arte o el de literatura han quedado engullidos parcialmente dentro de la categoría de bienes de consumo. Edmond Cros comenta en su Literatura, ideología y sociedad (1986) la teoría de Bourdieu sobre la existencia de dos campos dentro de la producción literaria: por un lado estaría la «producción masiva», esta es la que está ligada al mercado y por lo tanto a las ventas, un ejemplo claro serían los best-sellers. Por el otro lado, y de manera más exclusiva, la «producción restringida», es decir, la literatura (entiéndase como aquella que no está producida con el único objetivo de ser comercializada a nivel masivo).

El movimiento posmodernista ha sido muy criticado. Lyotard atacó a la sociedad posmoderna por el poder que le concedía al dinero, ya que pensaba que esta se adecuaba a cualquier tendencia o necesidad siempre y cuando dispusiera de poder adquisitivo. Por su parte, Terry Eagleton tacha al posmodernismo de «derrota histórica» y critica que el capitalismo salvaje haya sido aceptado sin mostrar resistencia ante él: 
El poder del capital es ahora tan terriblemente familiar, tan sublimemente omnipotente y omnipresente que incluso vastos sectores de la izquierda han logrado naturalizarlo, tomándolo por garantizado como una estructura tan inmovible que apenas tuvieran coraje para hablar de él. [...] Con la conformidad de Darwin, gran parte de la izquierda cultural ha tomado el tono de su contexto histórico: si vivimos una época en la cual el capitalismo no puede ser exitosamente desafiado, se puede decir que no existe para todos los intentos y propósitos. (Eagleton, 1998: 47)

El filósofo esloveno Slavoj Žižek da su opinión sobre la relación del capitalismo con el posmodernismo. Afirma que la lógica posmodernista no funciona bajo los preceptos capitalistas sino que la ideología capitalista utiliza el multiculturalismo pregonado por los posmodernos como herramienta de «colonización». En la introducción de su obra En defensa de la intolerancia (2008) Žižek aboga por la politización de la economía para frenar el abuso capitalista:

Esta forma hegemónica del multiculturalismo se basa en la tesis de que vivimos en un universo post-ideológico, en el que habríamos superado esos viejos conflictos entre izquierda y derecha, que tantos problemas causaron, y en el que las batallas más importantes serían aquellas que se libran por conseguir el reconocimiento de los diversos estilos de vida. Pero, ¿y si este multiculturalismo despolitizado fuese precisamente la ideología del actual capitalismo global? (Žižek, 2008: 11)

Según los anteriores argumentos el posmodernismo se muestra como síntoma del establecimiento de un capitalismo tardío en una sociedad que ha normalizado el discurso capitalista, sin ningún contrapeso ideológico desde la caída de la Unión Soviética, y en la cual los mass media ahora tienen el control de la opinión pública. Este poder le permite a los medios de comunicación, en connivencia con los mercados, ser un regulador de tendencias culturales. Es justo esta capacidad de alienar al hombre, tratado ya como un potencial consumidor, la que favorece al conjunto social sobre el individuo. La «masificación» de éste es una imposición ideológica del capitalismo, la mercantilización se ha propagado al terreno cultural y la propuesta posmodernista se ha tornado nihilista. Todo tiene un precio y todo es tratado como un bien de consumo. 


\section{El imaginario poético español en el último tercio del siglo XX}

En 1975 muere el dictador Francisco Franco, iniciándose con su deceso un proceso de apertura democrática que culminaría con la convocatoria de las primeras elecciones en 1977 y la aprobación de la Constitución en 1978. De alguna manera la caída del régimen de forma consensuada y paulatina permitió que, pese a la llegada de la democracia, el franquismo hubiera tomado otra forma y se hubiera integrado en la sociedad. Las negociaciones políticas durante la Transición buscaron la armonía pacífica entre los partidos y se iniciaron los cambios gubernativos y sociales tomando un cariz reformista cuando debieron ser rupturistas, por lo menos si la intención era iniciar una etapa democrática libre de cargas franquistas. Posiblemente de haberse impuesto la corriente rupturista la estabilidad democrática y la económica del momento se hubieran quebrado.

Sobre la aparición y asimilación del posmodernismo, la hispanista Alison Maginn (1998: 153) corrobora en su artículo «La España posmoderna: pasotas, huérfanos y nómadas» cómo «a finales de los setenta la posmodernidad salta a la palestra en España». Probablemente el fin de la censura gubernamental, en 1977, permite que se inicie el periodo literario posmodernista sin que exista ningún factor político que pueda impedir su expresión. No obstante, el concepto «posmodernidad» en España resulta, en el mejor de los casos, igual de discutido que a nivel mundial. Al no existir una definición concreta aceptada mayoritariamente, la clasificación de los autores o del propio movimiento es siempre motivo de disputa entre los críticos literarios.

A lo largo de la centuria pasada, mucho antes de la asimilación social del movimiento, se pueden vislumbrar elementos de tinte posmodernista. El profesor Ángel del Río, en su volumen titulado Historia de la literatura española, II. Desde 1700 basta nuestros días, detecta a principio del siglo XX una ruptura con el movimiento predominante:

Si comparamos los escritores de comienzos de siglo con los que continúan su obra, aquéllos tienen acaso una individualidad mayor, pero son incapaces de una acción cohesiva, no logran elevar el ambiente cultural ni crear escuela. Su estilo es puramente personal, y a lo sumo van a servir de estímulo para los jóvenes. Unamuno, Azorín, Baroja, Valle Inclán acusan su singularidad, son grandes solitarios interesados en crearse un mundo que puede desentonar en el estilo intelectual de Europa 
entre las dos guerras. Ortega, d'Ors, Gómez de la Serna, Madariaga, Juan Ramón, en trance de renovación constante, los investigadores y críticos de la escuela de Menéndez Pidal, los poetas de la generación del 27 son, sin dejar de ser españoles, voces europeas. (Del Río, 2011: 342)

En lo referente al género de la poesía, en la década de los 40 se empieza a manifestar un cambio de forma en la poética: un giro temático hacia lo social, contenido existencialista y una pérdida de la intención estética predominante en los años 20. Los principales autores donde se aprecia esta evolución son Dámaso Alonso y Blas de Otero. Poco antes, en 1938, Antonio Machado publica varios artículos a los que llamó «Desde el mirador de la guerra. Viejas profecías de Juan de Mairena» donde ya hace alusión en clave vanguardista a la crisis del modernismo:

¿Surgirá un arte nuevo? Esa pregunta sobradamente inepta, carecerá de sentido. Porque lo primero que ha de empaparse con una esponja empapada en la vieja sangre de los hombres es el prurito de discontinuidad y de creación del ex nihilo que se engendró en una posguerra embrutecida y desorientada. (citado en Alonso, 1985: 374)

Existe el acuerdo común, como pone de manifiesto Sobejano-Morán en Metaficción española en la postmodernidad (2003), que reconoce a Federico Onís como el primer autor en usar el término «posmodernidad»:

Federico de Onís, en su Antología de la poesía española e bispanoamericana (1882-1932), publicada en Madrid en 1934, fue el primer crítico en hablar de postmodernismo como reacción contra el modernismo, un movimiento fundamentalmente poético y de filiación latinoamericana. (Sobejano-Morán, 2003: 1)

Por su parte, el hispanista Víctor Fuentes habla en su artículo «De la vanguardia a la posmodernidad: hitos configuradores de la literatura en español» (1994: 113-114) de la reflexión de Francisco Ayala en 1947, durante su exilio en Argentina, donde cuestiona la «literatura del agotamiento». Ayala critica que las vanguardias hayan llegado al extremo de «lo nuevo por lo nuevo». También hace referencia al ex nibilo proponiendo una revisión del pasado que, no pudiendo ser destruido porque nos destruiría a nosotros mismos, debe estar carente de inocencia, es decir, sugiere una relectura irónica sobre él. 
Curiosamente, aproximadamente veinte años después en clara sintonía con este pensamiento, Umberto Eco y John Barth teorizarían sobre la posmodernidad utilizando estos términos. Fuentes continúa su artículo haciendo alusión a un hito que resultó ser un punto de inflexión en lo que se refiere al reconocimiento del nuevo paradigma posmodernista: En 1951, cuando se empieza a reconocer al nuevo movimiento, Ortega y Gasset, uno de los precursores españoles, anuncia en su célebre coloquio de Darmstadt «la muerte de la modernidad» debido al fin de la idea de los metarrelatos.

El profesor Julio Rodríguez explica, en su aportación a la publicación colectiva Del franquismo a la posmodernidad. Cultura española 1975-1990, la crisis del realismo español apreciada entre los años 1962 y 1965 . Las nuevas tendencias acusan al realismo de «contenutismo», es decir, de primar el mensaje por encima de la forma, estructura y lenguaje. Probablemente la decadencia del régimen hacía pensar que ya no era necesaria una literatura de denuncia y que había que regresar al concepto de literatura clásica, lo que supone la división de una literatura para el público culto y burgués y otra para el «popular», que estaría influenciada por los ahora numerosos e influentes medios de comunicación (Rodríguez Puértolas, 1995: 267).

Una de las primeras veces que un crítico español utiliza el término «posmodernismo» es en 1962, cuando Ricardo Gullón realiza la introducción del libro Juan Ramón y el modernismo. Para Gullón el fenómeno posmodernista llega tras medio siglo de modernismo, datando la duración de este movimiento aproximadamente entre 1890 a 1940. Su visión está acorde con la de los críticos norteamericanos que veían en ese momento la corriente posmodernista desde un punto de vista pesimista (Fuentes, 1994: 115).

Más concretamente en lo que se refiere al género poético, el profesor Andrew P. Debicki afirma que la poesía posmoderna irrumpe con la generación del 68 y su lírica «novísima». En 1988 comenta lo siguiente sobre los cambios que aparecieron en la nueva poética emergente:

Por eso quisiera hacer destacar en este trabajo otros cambios que ocurren en la poesía española de las últimas décadas, y que tienen más que ver con el enfoque del poema, el juego de perspectivas y ciertos rasgos metapoéticos que con su temática. Los poemas que voy a comentar se distinguen por su empleo simultáneo de diversos niveles de lenguaje y de diversas perspectivas, que nunca se resuelven en un significado 
unitario, dejando al lector la tarea de barajarlos y llegar a alguna conclusión. En muchos casos, esto se combina con alusiones al poema mismo y a sus procedimientos dentro del texto, motivando un rompimiento de la convención de que la realidad descrita en la obra es una ficción separada de la realidad del autor (y del lector). Todas estas tensiones, irresoluciones y aspectos metapoéticos podrán relacionarse, en mi opinión, con la pérdida de confianza en la unicidad e inmutabilidad de la obra que se ha visto como el paso desde la modernidad a la postmodernidad. (Debicki, 1988: 166)

En la misma línea, en su artículo «La posmodernidad en la poesía contemporánea española: la búsqueda de los orígenes» (2011) la profesora Eva Álvarez afirma que:

En la década de los setenta los rasgos posmodernos se manifiestan de manera directa y nada equívoca y podemos hablar, con pleno derecho y sin lugar a ambigüedades, de una poesía cien por cien posmoderna amparada por el apoyo de todos los críticos que coinciden en señalar una clara ruptura con todo lo anterior. (Álvarez Ramos, 2011: 34)

Para Álvarez «el poema se concibe como un cúmulo de indeterminaciones que el lector debe actualizar y debe estructurar para alcanzar, de ese modo, el significado del mismo» (2011: 28). Por lo tanto, suscribe la teoría de Umberto Eco sobre la «obra abierta». Este nuevo enfoque fuerza la recepción del texto sin consensuar la postura del autor al respecto. Esto significa que se abre un proceso lleno de ambigüedades donde se invita al lector a participar en la «creación y recreación» de la obra. Según Álvarez, estas nuevas relaciones provocan procesos desestabilizadores que se traducen en el uso de lenguas diferentes, diversos niveles lingüísticos, técnicas como el collage, la carnavalización, la parodia o el pastiche. Para Hal Foster, uno de los principales especialistas en la estética posmoderna, el «pastiche es el estilo oficial del campo posmoderno» (citado en Álvarez Ramos, 2011: 30).

Jenaro Talens, en su capítulo del libro Del franquismo a la posmodernidad, trata pormenorizadamente el devenir de la poesía a partir de los años 60 en España. En su opinión, los criterios que han canonizado la poesía de aquella década en adelante no se deben a pautas académicas sino a razones ideológicas y comerciales. Para ejemplificar esta construcción historiográfica usa el auge del boom 
hispanoamericano. Talens describe este fenómeno como una «operación comercial tan lucida como inteligente» en la cual el editor Carlos Barral, que por entonces dirigía la editorial Seix-Barral, introdujo en el mercado español, y posteriormente en el europeo, nombres de autores de cuya calidad nadie duda hoy en día. El reproche va dirigido hacia la crítica académica, la cual asume «su producto como nómina-modelo desde la que juzgar el trabajo literario de todo un continente hasta entonces bastante poco conocido al gran público» (Talens, 1995: 62). Esto provocó que, cuando la novela hispanoamericana se incorpora a los planes de estudios, los autores elegidos fueron aquellos que formaron parte del boom. Talens presenta su visión sobre estos hechos:

El problema historiográfico que este mecanismo representa es particularmente grave, porque incluso cuando muchos juicios apresurados sean corregidos y algunos nombres injustamente silenciados se incorporen con posterioridad al relato histórico de la literatura, rara vez sucede que dichos cambios modifiquen el marco genérico donde se insertan, al menos, de manera más o menos inmediata. (Talens, 1995: 63)

En lo referente a la creación del «canon español contemporáneo», la criba de autores españoles es expuesta con varios ejemplos durante el capítulo. El primero de ellos es la antología Veinte años de poesía española (1939-1959) (Castellet, 1960). Según Benito Fernández en su obra El contorno del abismo (2006) Jaime Gil de Biedma reconoce que varios poetas quedaron excluidos por razones «no estrictamente literarias»; entre los descartados estaba Alfonso Costafreda. Talens (1995) opina que una vez perdida la oportunidad generacional y el impulso publicitario difícilmente un autor podrá competir con aquellos poetas con mayor apoyo bibliográfico aunque su calidad sea cuanto menos igual. El siguiente ejemplo de «canonización» es la célebre antología del mismo Castellet de 1970, Nueve novísimos poetas españoles. Por primera vez en una antología se formulaba una hipótesis previa y se intentaba crear una colectividad a partir de nombres en su mayoría desconocidos. Talens cree que «Si el nombre del antólogo no hubiera sido el que es ni la casa editora la que fue, posiblemente el carácter canónico que ha acompañado al libro durante todos estos años no habría existido» (Talens, 1995: 72). Entre los poetas seleccionados estaba el joven Leopoldo María Panero, que contaba por entonces con apenas veinte años. Como respuesta a esta antología poco convencional de Castellet a los meses aparece Nueva poesía española (Martin Prado, 1970). En esta nueva propuesta se mantienen la mayoría de los nombres pero se dejan fuera las 
posturas más radicales de la antología de Castellet, esto es Vázquez Montalbán y el joven Panero. En 1976 el libro de los nueve novísimos tiene una versión italiana pero al traducirlo se han excluido, sin saber quién ni porqué, a cuatro autores. Por lo tanto, esta política de selección de autores es comprensible si, como Talens asegura, la Historia de la Literatura está inserta en una serie de discursos institucionadores:

[...] la Historia de la Literatura debería ser abordada como la Historia del proceso de institucionalización social de una práctica discursiva. Desplazando el punto de articulación desde el proceso de producción del objeto hacia el proceso de reproducción (esto es, lectura) del mismo puede analizarse lo artístico-literario desde el interior de una formación social en su presente. (Talens, 1995: 84)

A partir de principios de los setenta se empieza a definir la poesía emergente «desde planteamientos y con características más acordes a los gustos dominantes y, en consecuencia, más asimilable por la crítica establecida» (Talens, 1995: 73).

\section{Conclusión}

Para analizar la asimilación de los rasgos posmodernistas por parte de la cultura española es necesario entender las imposiciones provenientes de los poderes fácticos que aún disponían de posiciones de autoridad en los años finales de la dictadura franquista. Entre las medidas de control que ostentaban estos poderes se encontraba el control de las publicaciones y el uso de la censura, lo que dificultaba que las nuevas corrientes que se expandían por el resto del mundo occidental llegasen a España de manera íntegra o simplemente llegasen. A pesar de la represión ideológica del gobierno de Franco la apertura que tiene lugar en los años 60 da lugar a un auge económico de la población permitiendo la eclosión de los mass media. Los nuevos medios culturales (cine, radio, comics...) influyen en el imaginario español. Pronto los personajes de cine o de las novelas gráficas eran populares entre los más jóvenes integrándose así en la cultura española de entonces. Los escritores y poetas no eran ajenos a esta asimilación cultural y comienzan a establecer como usuales las prácticas del movimiento posmodernista poniéndose de moda el uso del pastiche, los elementos intertextuales y demás prácticas de dicha corriente. 
La apertura de los años 6o, la transformación cultural a partir de los mass media y un sistema económico que se encontraba en pleno auge gracias a las inyecciones económicas de Estados Unidos también liberó el mercado. Con las editoriales con libertad de movimiento, dentro de los márgenes de la censura, se inicia una batalla en el campo de juego del capitalismo para imponer a sus propios autores. El canon literario, que hasta el momento había sido construido desde el posicionamiento ideológico, empieza a ser influido por intereses económicos.

Es en los años 80 cuando el posmodernismo, como expresión artística y literaria, se muestra en su máximo esplendor en España. La expresión creativa se muestra contestataria ante el nuevo régimen democrático, pero esa reacción subversiva se limita a una postura meramente estética. Las recientes prácticas capitalistas logran borrar del discurso artístico y literario toda referencia, directa o indirecta, a la lucha de clases. La nueva izquierda democrática se limita a representar un papel de oposición a la derecha sin suponer una alternativa real.

De acuerdo con esta exposición y al rigor de los hechos presentados podemos llegar a la conclusión de que como consecuencia del final del aislamiento internacional a partir de los años 60 en España tiene lugar un desarrollo del tardocapitalismo que se enraizó en la sociedad española a través de los mass media. A consecuencia de esto se adoptó entonces una nueva cultura de consumo rápido, mercantilizando toda práctica que fuera susceptible de crear grandes plusvalías, de esta manera la producción artística y literaria se orienta en este sentido. Los mercados y los mass media se consolidan como núcleos de influencia con capacidad de regular tendencias de consumo. Las editoriales asimilan este nuevo panorama comercial transformado a sus escritores en marcas, lo que significa que la calidad de sus obras pasa a un segundo plano bajo la maquinaria publicitaria que genera el propio nombre del literato.

\section{Bibliografía}

Alonso, M. (1985): Antonio Machado: poeta en el exilio. Barcelona: Anthropos.

Álvarez Ramos, E. (2011): «La posmodernidad en la poesía contemporánea española: la búsqueda de los orígenes». OGIGIA, 10, 25-38.

Benítez Fernández, J. (2006): El contorno del abismo. Barcelona: Tusquets.

Blanco Gálvez, J.A. (2007): «La "Ética de la interpretación”, de Gianni Vattimo, en el Contexto de la Posmodernidad». A Parte Rei, 54, 1-142.

Castellet, J.M. (1960): Veinte años de poesía española (1939-1959). Barcelona: Six Barral. 
Castellet, J.M. (1970): Nueve novísimos poetas españoles. Barcelona: Six Barral.

Cros, E. (1986): Literatura, ideología y sociedad. Madrid: Gredos.

Debicki, A. P. (1988): «Poesía española de la postmodernidad». Anales de Literatura Española, 6, 165-180.

Del Río, Á. (2011): Historia de la literatura española, II. Desde 1700 basta nuestros días. Madrid: Gredos.

Eagleton, T. (1998): Las ilusiones del posmodernismo. Buenos Aires: Paidós.

Fuentes, V. (1994): «De la vanguardia a la posmodernidad: hitos configuradores de la literatura en español». En: Villegas, J. (ed.): Actas de XI Congreso de la Asociación Internacional de Hispanista. Santa Bárbara: Universidad de California.

Jaime Garza, M.S. (2001): Ética y posmodernidad. Tesis doctoral. Universidad Autónoma de Nuevo León, Facultad de Filosofía y Letras.

Jameson, F. (1991): Ensayos sobre el posmodernismo. Buenos Aires: Imago Mundi.

Lyotard, J.F. (1989): La condición posmoderna: informe sobre el saber. Madrid: Cátedra.

Machado, A. (1938): «Desde el mirador de la guerra. Viejas profecías de Juan de Mairena». La Vanguardia, 24 de agosto.

Maginn, A. (1998): «La España posmoderna: pasotas, huérfanos y nómadas». En: Ward, A. M., Whicker, J., Flitter, D. W., Dadson, T. J., y Odber de Baubeta, P. (eds.): Actas de XII Congreso de la Asociación Internacional de Hispanista. Birmingham: University of Birmingham.

Ortega y Gasset, J. (2010): Obras completas, Tomo X. Madrid: Taurus.

Rodríguez Puértolas, J. (1995): «Democracia, Literatura y Poder». En: Monleón, J. B. (ed.): Del franquismo a la posmodernidad. Cultura española 19751990. Madrid: Akal, 267-282.

Sobejano-Morán, A. (2003): Metaficción Española en la Postmodernidad. Kassel: Reichenberger.

Talens, J. (1995): «De la publicidad como fuente historiográfica: la generación poética española de 1970». En: Monleón, J. B. (ed.), Del franquismo a la posmodernidad. Cultura española 1975-1990. Madrid: Akal, 57-83.

Vattimo, G. (2004): Nibilismo y emancipación: ética, politica, derecho. Barcelona: Paidós.

Žižek, S. (2008): En defensa de la intolerancia. Madrid: Sequitur. 
Fernando Candón Ríos

University of Cádiz

\section{Postmodern Spanish Literature between the end of the dictatorship and the rise of mass media}

Keywords: Spanish Culture, Mass media, Postmodernism, Spanish literature, Contemporary poetry.

In this article we discuss the assimilation of postmodern practices into Spanish culture, specifically in the field of literature. Spain remained internationally isolated during the first phase of the Franco dictatorship, which prevented new cultural movements arising in Europe and America from becoming established in Spain. It was not until the economic boom of the 6os that the mass media was imposed as a cultural regulator, commercializing all artistic production and spawning new trends in cultural consumption. The new mass media served as a cultural bridge between Spain and the rest of the world, enabling the Spanish population to become part of a new globalized world. 
Fernando Candón Ríos

Univerza v Cádizu

\section{Španska postmoderna književnost: med koncem diktature in vrhuncem množičnih občil}

Ključne besede: španska kultura, množična občila, postmoderna, španska književnost, sodobna poezija

V pričujočem članku bomo analizirali asimilacijo postmodernih praks $v$ španski kulturi, natančneje, na področju književnosti. Španija je bila v prvem obdobju frankistične diktature osamljena in odmaknjena od mednarodnega dogajanja, kar je novim kulturnim oblikam, ki so se razvijale v Evropi in Ameriki, onemogočilo, da bi se uveljavile na njenem ozemlju. Šele z gospodarskim »boomom《v šestdesetih letih so množična občila prevzela narekovanje kulturnih smernic, tržno usmerila celotno umetniško produkcijo in zaznamovala potrošniške težnje. Novi množični mediji so bili kulturni most med Španijo in tujino in tako je španska družba postala del novega globaliziranega sveta. 